\title{
Associations between urinary metabolites of di(2-ethylhexyl) phthalate and reproductive hormones in fertile men
}

\author{
J. Mendiola ${ }^{\star}$, N. Jørgensen ${ }^{\dagger}$, A.-M. Andersson ${ }^{\dagger}$, A. M. Calafat ${ }^{\ddagger}$, M.J. Silva ${ }^{\ddagger}$, J.B. Redmon ${ }^{\S}$, \\ A. Sparks II, E.Z. Drobnis ${ }^{\star *}$, C. Wang ${ }^{\dagger \dagger}$, F. Liu", and S.H. Swan ${ }^{\star}$ \\ "Department of Obstetrics and Gynecology, School of Medicine and Dentistry, University of \\ Rochester, Rochester, NY, USA \\ tUniversity Department of Growth and Reproduction, University of Copenhagen, Rigshospitalet, \\ Copenhagen, Denmark
}

‡Division of Laboratory Sciences, National Center for Environmental Health, Centers for Disease Control and Prevention, Atlanta, GA

$\S$ Departments of Medicine and Urologic Surgery, University of Minnesota Medical School, Minneapolis, MN

IDepartment of Obstetrics and Gynecology, University of lowa, lowa City, 10

${ }^{* *}$ Department of Obstetrics, Gynecology and Women's Health, School of Medicine, University of Missouri, Columbia, MO

t†Division of Endocrinology, Department of Medicine, Harbor-UCLA Medical Center and Los Angeles Biomedical Research Institute, Torrance, CA, USA

\section{Summary}

\begin{abstract}
Widely used man-made chemicals, including phthalates, can induce hormonal alterations through a variety of cellular and molecular mechanisms. A number of rodent and observational studies have consistently demonstrated the anti-androgenic effect of several phthalates. However, there are only limited data on the relationship between exposure to these chemicals and reproductive hormone levels in men. All men $(n=425)$ were partners of pregnant women who participated in the Study for Future Families in five US cities and provided urine and serum samples on the same day. Eleven phthalate metabolites were measured in urine and serum samples were analysed for reproductive hormones, including follicle-stimulating hormone, luteinizing hormone, testosterone, inhibin B and oestradiol and sex hormone-binding globulin (SHBG). Pearson correlations and parametric tests were used for unadjusted analyses, and multiple linear regression analysis was performed controlling for appropriate covariates. We observed weak or no associations with urinary phthalates other than di(2-ethylhexyl) phthalate (DEHP). All measures of testosterone [total, calculated free testosterone and the free androgen index (FAI)] were inversely correlated with the urinary concentrations of four DEHP metabolites. After adjustment by appropriate covariates, there was no longer an association between urinary DEHP metabolite concentrations and total testosterone levels; however, FAI was significantly associated with the urinary concentrations of several DEHP metabolites. SHBG was positively related to the urinary concentrations of mono(2-ethylhexyl) phthalate, but not with other DEHP metabolites, an association that was attenuated after adjustment. Our results suggest that DEHP exposure of fertile men is associated with minor alterations of markers of free testosterone.
\end{abstract}




\section{Keywords}

anti-androgens; di(2-ethylhexyl) phthalate metabolites; endocrine disruptors; male hormones; phthalates

\section{Introduction}

Recent studies have reported secular declining trends in testosterone levels (Andersson et al., 2007; Travison et al., 2007) consistent with decreases in semen quality (Carlsen et al., 1992; Swan et al., 1997). Although exposure data are limited, it has been hypothesized that these changes might concur with increasing human exposure to endocrine-disrupting compounds (Sharpe \& Skakkebaek, 2008; Jørgensen et al., 2010). Phthalates are extensively used in industry and commerce as components of foods, personal care products and plasticizers (ATSDR, 2002). A majority of US residents have detectable concentrations of several phthalates in urine, indicating that exposure to the parent diester compounds is common among the general population (CDC, 2009). A growing body of toxicological studies has shown associations between several of these phthalates and adverse reproductive effects (Hauser \& Calafat, 2005; Meeker et al., 2009a). Briefly, dibutyl phthalate (DBP), benzylbutyl phthalate, di(2-ethylhexyl) phthalate (DEHP), and di-isononyl phthalate have been shown to disrupt reproductive tract development (e.g. hypospadias, reduced foetal testosterone synthesis) in male rodents as a result of anti-androgenic action (Gray et al., 2000; Parks et al., 2000). Germ cells are also considered the primary targets of phthalate toxicity (Akingbemi et al., 2004; Mahood et al., 2005; Foster, 2006). Both foetal and adult exposures to phthalates are suspected to contribute to impaired human fertility (Skakkebaek et al., 2001; Mahood et al., 2005). However, only a few human studies have looked into the association between male's reproductive hormones or hormone markers and phthalate exposures.

Regarding perinatal exposures, Main et al. (2006) investigated the relationship between the concentrations in human breast milk of several phthalate metabolite monoesters and postnatal reproductive serum hormones in newborn boys. They found positive associations between the concentrations in breast milk of some phthalate metabolites [monoethyl phthalate (MEP), mono- $n$-butyl phthalate (MBP)] with serum luteinizing hormone (LH)/free testosterone (FT) ratio, sex hormone-binding globulin (SHBG) and LH concentrations, as well as a negative association between MBP and calculated serum FT levels. Swan (2008) and Swan et al. (2005) evaluated anogenital distance (AGD) and other genital measurements in boys 2-36 months of age in relation to their mother's phthalate exposures measured (assessed by the concentrations of phthalate metabolites in prenatal urine samples). Urinary concentrations of MEP, MBP, monobenzyl phthalate (MBzP) and monoisobutyl phthalate (MiBP) were inversely related to AGD, a marker of incomplete virilization in rodents, supporting the hypothesis that prenatal phthalate exposure may adversely affect male reproductive development in humans also.

Pan et al. (2006) studied adult men occupationally exposed to phthalates showing that exposure to DEHP and DBP was negatively associated with FT serum levels. In a Swedish population of young men, Jonsson et al. (2005) reported an inverse association between urinary MEP concentration and LH values, although no association was found between other phthalate metabolites and other reproductive hormones. Duty et al. (2005), in a male population attending a fertility clinic, reported a negative association between urinary concentrations of MBzP with follicle-stimulating hormone (FSH) serum levels, but a positive association for MBP and inhibin $\mathrm{B}$. 
Recently, Meeker et al. (2009b) extended the work of Duty et al. (2005) by including a larger sample size and expanding the number of hormones and phthalate metabolites measured. The authors found that the urinary mono(2-ethylhexyl) phthalate (MEHP) concentration was negatively associated with testosterone, oestradiol $\left(\mathrm{E}_{2}\right)$ and free androgen index (FAI) levels, suggesting that exposure to DEHP may be associated with altered sex steroid hormones in some men.

The overall aim of this study was to examine the associations reported by Meeker et al. (2009b) in a population of fertile men.

\section{Materials and methods}

\section{Study population}

All men were participants in the Study for Future Families (SFF), a multicentre study of pregnant women and their partners, conducted at prenatal clinics affiliated with university hospitals in five US cities (Harbor-UCLA and Cedars-Sinai Medical Center in Los Angeles, CA, USA; University of Minnesota Medical Center in Minneapolis, MN, USA; University Physicians in Columbia, MO, USA; Mt. Sinai School of Medicine, New York City, NY, USA; and University of Iowa, Iowa City, IA, USA) between 1999 and 2005. Methods for clinical examination, data collection and semen analysis, which were standardized across centres, have been described previously (Swan et al., 2003). Briefly, couples were recruited at the prenatal clinic and only those whose pregnancy was conceived without medical assistance were eligible. The men completed a questionnaire, received a physical examination and gave a urine sample within 15 min after the blood was drawn. These men were presumed to be the biological father of the pregnancy based on their statements and that of the partner. Questions for them included demographics, recent fever, history of sexually transmitted diseases, as well as lifestyle factors (smoking, alcohol and caffeine consumption) and diet. The involvement of Centers for Disease Control and Prevention (CDC) laboratory was limited and determined not to constitute engagement in human subjects' research. Human subject approvals were obtained from Institutional Review Boards at all participating institutions.

\section{Serum hormones analysis}

Venous blood samples were drawn, and the serum was separated and frozen at $-80{ }^{\circ} \mathrm{C}$. All samples were analysed for hormones in the same laboratory at the Rigshospitalet (Copenhagen, Denmark). Samples were shipped to Copenhagen on dry ice and stored at -20 ${ }^{\circ} \mathrm{C}$ until analysis was performed. This methodology has been described previously elsewhere (Bang et al., 2005; Asklund et al., 2007). Briefly, hormone assessments were performed simultaneously to reduce intralaboratory variations. Serum levels of FSH, LH and SHBG were determined, using a time-resolved immunofluorometric assay (DELFIA, Perkin Elmer, Denmark). Testosterone levels were determined using a time-resolved fluoroimmunoassay (DELFIA), and $\mathrm{E}_{2}$ by radioimmunoassay (Pantex, Santa Monica, USA). Inhibin B levels (Oxford-Bioinnovation, UK) were determined by a specific two-sided enzyme immunometric assay. Intra- and interassay coefficients of variation $(\mathrm{CV})$ for measurements of both FSH and LH were 3 and $4.5 \%$, respectively. CV for both testosterone and SHBG were $<8$ and $<5 \%$, and CV for inhibin B were 15 and $18 \%$, respectively. To estimate the biologically available levels of free testosterone, two measures were used. FAI was calculated as (total testosterone)/(SHBG $\times 100)$. FT is a measure of free testosterone calculated from concentrations of total testosterone, albumin and SHBG along with testosterone-binding constants to albumin and SHBG. FT concentration was calculated using the equation of Vermeulen et al. (1999). 


\section{Urinary phthalate metabolite measures}

The concentrations of urinary phthalate metabolites in 425 men were determined at the Division of Laboratory Sciences, National Center for Environmental Health, CDC (Atlanta, GA); CDC researchers had no access to participant data. Urinary samples were frozen and stored at $-80^{\circ} \mathrm{C}$, and then were shipped to $\mathrm{CDC}$ on dry ice. Phthalate metabolites were measured in urine to avoid potential sample contamination from the parent diester and because the metabolites (not the parent diesters) are supposed to be the active toxicants (Li et al., 1998). The analytical approach to the analysis of urinary phthalate metabolites is a modification of previously published methods and has been described previously (Silva et al., 2007). Briefly, the analysis involves the enzymatic deconjugation of the phthalate metabolites from their glucuronidated form, automated online solid-phase extraction coupled with separation with high-performance liquid chromatography, and detection by isotope-dilution tandem mass spectrometry. This high-throughput method allows for the concurrent quantification in human urine of the 11 phthalate metabolites reported in this work. Limits of detection (LOD) are in the low nanogram per millilitre range. Isotopically labelled internal standards were used along with conjugated internal standards to increase precision and accuracy of the measurements. The method is accurate (spiked recoveries are near $100 \%$ ), and precise with between-day relative standard deviations of $<10 \%$. Quality control samples and laboratory blanks were analysed along with unknown samples to monitor performance of the method (Swan et al., 2005). Concentrations are reported in ng/ $\mathrm{mL}$. Eleven phthalate metabolites were measured [MEHP, mono(2-ethyl-5-hydroxyhexyl) phthalate (MEHHP), mono(2-ethyl-5-oxohexyl) phthalate (MEOHP), mono(2-ethyl-5carboxypentyl) phthalate (MECPP), mono(3 carboxypropyl) phthalate (MCPP), MEP, MBzP, MBP, monocarboxyisononyl phthalate (MCNP), monocarboxyisooctyl phthalate (MCOP) and MiBP]. In addition to examining associations with each metabolite, we explored the associations between reproductive hormones and the sum of the urinary DEHP ( $\mathrm{DEHP}$ ) metabolite concentrations [sum of MEHP, MEHHP, MEOHP and MECPP concentrations (in $\mathrm{nmol} / \mathrm{mL}$ ); Hauser et al., 2006].

\section{Statistical analyses}

As the frequency distribution of serum hormones (except $E_{2}$ ) and phthalate metabolites' urinary concentrations were skewed (non-normal) distributions, these variables were logarithmically $\left(\log _{10}\right)$ transformed before analysis. In preliminary analyses (unadjusted), Pearson correlation coefficients and parametric tests were used to explore the relationship between each hormone concentration and each phthalate metabolite concentration. Multiple linear regression analyses were then performed controlling for appropriate covariates previously noted to be associated with male reproductive function, including age, age square, body mass index (BMI), smoking status (current smoker vs. never smoked), ethnicity [(African-American vs. others) because of relevance of racial and ethnic differences in sex steroids; Wang et al., 2007], urinary creatinine concentration, time of sample collection (number of hours after 7:00 am of serum and urinary collection) and time of collection squared. Other covariates (i.e. season, educational level, centre and stressful live events) were also explored, but were not retained in the final models. Age, BMI, urinary creatinine concentration and time of sampling were modelled as continuous variables, all others as dichotomous variables. Only four men used any hormonal medication, but in any case, to be a confounder, these medications would have to also be related to DEHP exposure and this is not a common use for DEHP. Most metabolite concentrations were above the LOD; those below the LOD were assigned a value of LOD divided by $\sqrt{2}$, which has been recommended when the data are not highly skewed, as was the case here (Hornung \& Reed, 1990). Data analysis was performed by two analysts using sas v9.1 (SAS Institute Inc., Cary, NC, USA) and spss v17.0 (SPSS Inc., Chicago, IL, USA). 


\section{Results}

Although 950 men participated in SFF, urine was not collected until the second year of the study. Of the 847 men who provided a blood sample, urinary phthalate metabolite concentrations were available for 425 individuals (50.2\%), except for $\mathrm{E}_{2}$ and inhibin B levels, which were only available for 405 and 424 men, respectively. Information on all covariates was available for 363 individuals, who were included in the final analysis. Summary statistics for men's reproductive hormones are presented in Table 1. The mean age [in years \pm standard deviation (SD)] and BMI (in $\mathrm{kg} / \mathrm{m}^{2} \pm \mathrm{SD}$ ) were $32.2 \pm 6.2$ and $28.2 \pm$ 5.4 , respectively. Twenty-one per cent of the men were smokers and a majority were Caucasian (72\%).

We saw little or no associations with metabolites of phthalates other than DEHP (data not shown). We report here on the associations involving the four measured metabolites of DEHP (MEHP, MEHHP, MEOHP and MECPP). The urinary concentrations of phthalate metabolites (before creatinine adjustment) and percentages above the LOD are shown in Table 2. All men had detectable concentrations of at least one urinary DEHP metabolite. Mean and SD for urinary creatinine concentrations were $144 \pm 80.4 \mathrm{mg} / \mathrm{dL}$ (median= 139 $\mathrm{mg} / \mathrm{dL})$.

In simple pairwise correlations, testosterone (total, FAI and FT), decreased somewhat with age $(r=-0.11,-0.31,-0.24$ for testosterone, FAI and FT, respectively; all $p$-values $<0.05)$. Similarly, FSH and SHBG increased modestly with age ( $r=0.14$ and 0.15 , respectively; both $p$-values $<0.01)$. BMI was negatively correlated with testosterone, inhibin B, SHBG and FT ( $r=-0.43,-0.31,-0.45,-0.26$, respectively; all $p$-values $<0.01)$ and positively correlated with $\mathrm{E}_{2}$ and FAI ( $r=0.22$ and 0.10 , respectively; both $p$-values < 0.05$)$. We saw a smaller (positive) correlation between BMI and FAI, but it was driven by a small number of individuals with high BMI and very low SHBG. Other than these individuals, FAI and FT were highly correlated (data available on request). Table 3 shows correlation coefficients for men's reproductive hormones and creatinine-adjusted phthalate metabolite concentrations from initial univariate analysis. All measures of total or bioavailable testosterone were inversely correlated with urinary DEHP metabolite concentrations. SHBG levels were positively related to MEHP, but not with other urinary DEHP metabolite concentrations in the univariate analysis, an association that was attenuated after adjustment. Table 4 shows standardized regression coefficients (and $p$-values) for our final multivariate models. Although these parameters vary somewhat with the specific metabolite, we include results only for MEHP here. Results for other metabolites are similar (data available on request). Table 5 shows the results of the multivariate analysis for men's reproductive hormones and phthalate metabolite urinary concentrations. By comparing these entries with those in Table 4 , we see that for several of these, including age and BMI, associations between covariates and metabolites are stronger than those with DEHP metabolites. Although time of blood draw was not a confounder in these analyses, we included it because of its strong association with several hormones. After adjustment, there was no longer an association between urinary DEHP metabolite concentrations and total testosterone levels. However, there remained a weak negative association between FT (as reflected by FAI) and several individual urinary DEHP metabolites as well as the DDEHP metabolite concentrations. FAI/ LH ratio was also inversely associated with urinary MEHP concentrations.

Figure 1 shows the percentage change in men's reproductive hormones expected with an interquartile increase (25th-75th) in phthalate metabolite concentrations for a 32-year-old non-smoker with BMI of $28 \mathrm{~kg} / \mathrm{m}^{2}$. For this typical study subject, an increase in urinary concentrations of MEHP and oxidative metabolites (MEHHP and MEOHP) from the 25th to the 75 th percentile would be predicted to decrease FAI levels between 5\% and 8\%. 


\section{Discussion}

This is the first study to examine the relationships between phthalate exposure and reproductive hormones in fertile men. Our results suggest that among fertile men, increasing environmental exposure to DEHP is associated weakly with hormonal alterations that would tend to decrease free testosterone (as reflected by the FAI). Urinary concentrations of other phthalate metabolites were not strongly associated with serum hormones in this population of fertile men.

Our results are similar to those reported by Meeker et al. (2009b) who described these associations in men recruited at an infertility clinic, although they reported a significant inverse association between urinary MEHP concentration and both testosterone and $\mathrm{E}_{2}$ levels, not seen in our population. Although we observed a significant inverse correlation between testosterone and MEHHP and MEOHP concentrations, this association disappeared after covariate adjustment. Furthermore, although we saw a suggestive negative association between MEHP and $\mathrm{E}_{2}$ levels, it was weak and did not reach traditional levels of statistical significance.

However, as in Meeker et al. (2009b), we found significant inverse associations between FAI levels and three of the DEHP urinary metabolite (MEHP, MEHHP and MEOHP) concentrations and their sum. The similarity of this finding in these two populations is of interest because our two populations were quite different. Meeker et al. (2009b) studied male partners of couples living in Boston undergoing infertility investigation; we studied fertile men from five US cities whose female partners were mid-pregnant at the time they gave their samples. Moreover, these two populations were dissimilar in their reproductive hormone levels and phthalate metabolite concentrations. The median values for FSH was higher, serum testosterone lower and MEHP higher in men studied by Meeker et al. (2009b) compared with our population, suggesting that at least some of the infertile men had primary testicular dysfunction associated with higher FSH and lower testosterone. However, the outcomes of both studies are not inconsistent, and suggest that DEHP metabolites may act similarly on the male reproductive axis in these two populations.

We saw a decrease in calculated FT and FAI levels (markers of biologically active testosterone) with increasing DEHP exposure. Decreases in the free fractions of total testosterone may be related to higher SHBG levels, as discussed next. Although all men in our study had serum testosterone, FT and FAI within the reference range of our laboratory, these data [consistent with the known anti-androgenic effect of DEHP (Parmar et al., 1986; Heindel et al., 1989; Srivastava et al., 1990; Li et al., 1998, 2000; Higuchi et al., 2003; Talsness et al., 2009; Thompson et al., 2009)], suggest that current environmental levels of DEHP exposure may exert a negative effect on the endocrine function of healthy men. This finding is consistent with data suggesting that phthalates may inhibit expression of genes involved in steroidogenesis (cholesterol transport and the biosynthesis of testosterone) in rat foetal testis after in utero exposure to large doses of DEHP (Borch et al., 2006).

However, two recently published studies did not find any anti-androgenic effects of phthalates on human foetal Leydig cells activity (Huang et al., 2009; Lambrot et al., 2009). Huang et al. (2009) studied prenatal exposure to phthalates in infants and reported a significant negative correlation between amniotic fluid MBP and the anogenital index adjusted by birth weight in female infants only. Lambrot et al. (2009) investigated the effects of MEHP on the development of human foetal testis. Their main results demonstrated that phthalates alter the development of the germ cell lineage, but in contrast to results observed in the rat, phthalates did not affect steroidogenesis. Nonetheless, earlier studies (Swan et al., 2005; Main et al., 2006; Swan, 2008) suggest that prenatal phthalate 
exposure may adversely affect male reproductive function in infant humans. Our data can only address adult exposures and not reflect any effects of prenatal exposure given the short half-life of DEHP metabolites (Koch et al., 2006).

We also found a significant positive association between serum SHBG levels and urinary MEHP concentrations, but not with the other measured DEHP metabolites. Increased serum SHBG levels have been described as an indirect sign of reduced androgen activity (Belgorosky \& Rivarola, 1985). Increased serum SHBG levels lead to a reduction in FT, as SHBG is the major specific binding protein for testosterone, whereas testosterone is loosely bound to albumin. The fact that FAI and SHBG are statistically associated with DEHP urinary metabolite concentrations whereas testosterone individually is not suggests that the associations we observed in these measures of free testosterone are driven by changes in SHBG. The decrease in the FAI /LH ratio with increasing MEHP urinary concentrations suggests that the anti-androgenic effect of that metabolite - at least to some degree - is mediated via a negative effect on the function of Leydig cells in the testes. In addition, LH levels usually increase to compensate when testosterone or FT decreases because of a compromised testicular production, and we did not see that augmentation. However, considering the clear association between serum SHBG levels and MEHP, it is worth considering that DEHP may also affect the liver and SHBG synthesis, especially as rodent studies have shown that DEHP, DEHP metabolites and DBP significantly affect the liver (Lapinskas et al., 2005; Wyde et al., 2005; Eveillard et al., 2009).

Unadjusted urinary concentrations of DEHP metabolites in our subjects were very similar to concentrations measured in US men from the 2003-2004 National Health and Nutrition Examination Survey (NHANES; CDC, 2009). For example, the median and 75th percentiles values for MEHP in men from NHANES 2003-2004 were 2.2 and $6.0 \mathrm{ng} / \mathrm{mL}$, respectively, compared with 3.2 and $7.7 \mathrm{ng} / \mathrm{mL}$ in our study.

Our data were limited by the use of a single urine sample to assess phthalates exposure and a single serum sample to describe hormone function. However, several studies have shown that although the urinary concentrations of phthalate metabolites are variable, exposure can be adequately described by a single sample (Hoppin et al., 2002; Hauser et al., 2004; Teitelbaum et al., 2008). Similarly, a single sample can be used to classify men's reproductive hormones (Bjornerem et al., 2006).

In summary, our results suggest that among fertile men, increasing environmental exposure to DEHP is associated weakly with hormonal alterations that would tend to decrease markers of free testosterone.

\section{Acknowledgments}

The findings and conclusions in this report are those of the author and do not necessarily represent the official position of the CDC. The authors gratefully acknowledge Ella Samandar, James Preau and Jack Reidy (CDC, Atlanta, GA) for measuring the urinary concentrations of the phthalate metabolites. This study is supported by the following grants: the Danish Agency for Science, Technology and Innovation, grant no. 271070678 to N. Jørgensen; University of Iowa Center for Health Effects of Environmental Contamination cooperative project grant to A. Sparks; and the General Clinical Research Center at Harbor-UCLA Medical Center (MO1 RR00425) to C. Wang.

\section{References}

Akingbemi BT, Ge R, Klinefelter GR, Zirkin BR, Hardy MP. Phthalate-induced Leydig cell hyperplasia is associated with multiple endocrine disturbances. Proc Natl Acad Sci. 2004; 101:775780. [PubMed: 14715905] 
Andersson AM, Jensen TK, Juul A, Petersen JH, Jorgensen T, Skakkebaek NE. Secular decline in male testosterone and sex hormone binding globulin serum levels in Danish population surveys. J Clin Endocrinol Metab. 2007; 92:4696-4705. [PubMed: 17895324]

Asklund C, Jørgensen N, Skakkebaek NE, Jensen TK. Increased frequency of reproductive health problems among fathers of boys with hypospadias. Hum Reprod. 2007; 22:2639-2646. [PubMed: 17728352]

ATSDR. Toxicological Profile for di(2-ethylhexyl)phthalate (DEHP). Atlanta, GA: Agency for Toxic Substances and Disease Registry; 2002.

Bang AK, Carlsen E, Holm M, Petersen JH, Skakkebaek NE, Jørgensen N. A study of finger lengths, semen quality and sex hormones in 360 young men from the general Danish population. Hum Reprod. 2005; 20:3109-3113. [PubMed: 16006470]

Belgorosky A, Rivarola MA. Sex hormone binding globulin response to testosterone. An androgen sensitivity test. Acta Endocrinol. 1985; 109:130-138. [PubMed: 2860769]

Bjornerem A, Straume B, Oian P, Berntsen GK. Seasonal variation of estradiol, follicle stimulating hormone, and dehydroepiandrosterone sulfate in women and men. J Clin Endocrinol Metab. 2006; 91:3798-3802. [PubMed: 16835279]

Borch J, Metzdorff SB, Vinggaard AM, Brokken L, Dalgaard M. Mechanisms underlying the antiandrogenic effects of diethylhexyl phthalate in fetal rat testis. Toxicology. 2006; 223:144-155. [PubMed: 16690193]

Carlsen E, Giwercman A, Keiding N, Skakkebaek NE. Evidence for decreasing quality of semen during the past 50 years. BMJ. 1992; 305:609-613. [PubMed: 1393072]

CDC. Washington, DC: Centers for Disease Control and Prevention; 2009. Fourth National Report on Human Exposure to Environmental Chemicals. Available at: http://www.cdc.gov/exposurereport/

Duty SM, Calafat AM, Silva MJ, Ryan L, Hauser R. Phthalate exposure and reproductive hormones in adult men. Hum Reprod. 2005; 20:604-610. [PubMed: 15591081]

Eveillard A, Lasserre F, de Tayrac M, Polizzi A, Claus S, Canlet C, et al. Identification of potential mechanisms of toxicity after di-(2-ethylhexyl)-phthalate (DEHP) adult exposure in the liver using a systems biology approach. Toxicol Appl Pharmacol. 2009; 236:282-292. [PubMed: 19245819]

Foster PM. Disruption of reproductive development in male rat offspring following in utero exposure to phthalate esters. Int J Androl. 2006; 29:140-147. [PubMed: 16102138]

Gray LE Jr, Ostby J, Furr J, Price M, Veeramachaneni DN, Parks L. Perinatal exposure to the phthalates DEHP, BBP, DINP, but not DEP, DMP, or DOTP, alters sexual differentiation of the male rat. Toxicol Sci. 2000; 58:350-365. [PubMed: 11099647]

Hauser R, Calafat AM. Phthalates and human health. Occup Environ Med. 2005; 62:806-818. [PubMed: 16234408]

Hauser R, Meeker JD, Park S, Silva MJ, Calafat AM. Temporal variability of urinary phthalate metabolite levels in men of reproductive age. Environ Health Perspect. 2004; 112:1734-1740. [PubMed: 15579421]

Hauser R, Meeker JD, Duty S, Silva MJ, Calafat AM. Altered semen quality in relation to urinary concentrations of phthalate monoester and oxidative metabolites. Epidemiology. 2006; 17:682691. [PubMed: 17003688]

Heindel JJ, Gulati DK, Mounce RC, Russell SR, Lamb JC 4th. Reproductive toxicity of three phthalic acid esters in a continuous breeding protocol. Fundam Appl Toxicol. 1989; 12:508-518. [PubMed: 2731665]

Higuchi TT, Palmer JS, Gray LE Jr, Veeramachaneni DN. Effects of dibutyl phthalate in male rabbits following in utero, adolescent, or postpubertal exposure. Toxicol Sci. 2003; 72:301-313. [PubMed: 12655036]

Hoppin JA, Brock JW, Davis BJ, Baird DD. Reproducibility of urinary phthalate metabolites in first morning urine samples. Environ Health Perspect. 2002; 110:515-518. [PubMed: 12003755]

Hornung RW, Reed LD. Estimation of average concentration in the presence of non-detectable values. Appl Occup Environ Hyg. 1990; 5:46-51.

Huang PC, Kuo PL, Chou YY, Lin SJ, Lee CC. Association between prenatal exposure to phthalates and the health of newborns. Environ Int. 2009; 35:14-20. [PubMed: 18640725] 
Jonsson BA, Richthoff J, Rylander L, Giwercman A, Hagmar L. Urinary phthalate metabolites and biomarkers of reproductive function in young men. Epidemiology. 2005; 16:487-493. [PubMed: 15951666]

Jørgensen N, Rajpert-De Meyts E, Main KM, Skakkebæk NE. Testicular dysgenesis syndrome comprises some but not all cases of hypospadias and impaired spermatogenesis. Int J Androl. 2010; 33:298-303. [PubMed: 20132348]

Koch HM, Preuss R, Angerer J. Di(2-ethylhexyl)phthalate (DEHP): human metabolism and internal exposure - an update and latest results. Int J Androl. 2006; 29:155-165. [PubMed: 16466535]

Lambrot R, Muczynski V, Lécureuil C, Angenard G, Coffigny H, Pairault C, Moison D, Frydman R, Habert R, Rouiller-Fabre V. Phthalates impair germ cell development in the human fetal testis in vitro without change in testosterone production. Environ Health Perspect. 2009; 117:32-37. [PubMed: 19165384]

Lapinskas PJ, Brown S, Leesnitzer LM, Blanchard S, Swanson C, Cattley RC, Corton JC. Role of PPARalpha in mediating the effects of phthalates and metabolites in the liver. Toxicology. 2005; 207:149-163. [PubMed: 15590130]

Li LH, Jester WF Jr, Orth JM. Effects of relatively low levels of mono-(2-ethylhexyl) phthalate on cocultured Sertoli cells and gonocytes from neonatal rats. Toxicol Appl Pharmacol. 1998; 153:258-265. [PubMed: 9878596]

Li LH, Jester WF Jr, Laslett AL, Orth JM. A single dose of di-(2-ethylhexyl) phthalate in neonatal rats alters gonocytes, reduces sertoli cell proliferation, and decreases cyclin D2 expression. Toxicol Appl Pharmacol. 2000; 166:222-229. [PubMed: 10906286]

Mahood IK, Hallmark N, McKinnell C, Walker M, Fisher JS, Sharpe RM. Abnormal Leydig cell aggregation in the fetal testis of rats exposed to di(n-butyl) phthalate and its possible role in testicular dysgenesis. Endocrinology. 2005; 146:613-623. [PubMed: 15539561]

Main KM, Mortensen GK, Kaleva MM, Boisen KA, Damgaard IN, Chellakooty M, et al. Human breast milk contamination with phthalates and alterations of endogenous reproductive hormones in infants three months of age. Environ Health Perspect. 2006; 114:270-276. [PubMed: 16451866]

Meeker JD, Sathyanarayana S, Swan SH. Phthalates and other additives in plastics: human exposure and associated health outcomes. Philos Trans R Soc Lond B Biol Sci. 2009a; 364:2097-2113. [PubMed: 19528058]

Meeker JD, Calafat AM, Hauser R. Urinary metabolites of di(2-ethylhexyl) phthalate are associated with decreased steroid hormone levels in adult men. J Androl. 2009b; 30:287-297. [PubMed: 19059903]

Pan G, Hanaoka T, Yoshimura M, Zhang S, Wang P, Tsukino H, Inoue K, Nakazawa H, Tsugane S, Takahashi K. Decreased serum free testosterone in workers exposed to high levels of di- $n$-butyl phthalate (DBP) and di-2-ethylhexyl phthalate (DEHP): a cross-sectional study in China. Environ Health Perspect. 2006; 114:1643-1648. [PubMed: 17107847]

Parks LG, Ostby JS, Lambright CR, Abbott BD, Klinefelter GR, Barlow NJ, Gray LE Jr. The plasticizer diethylhexyl phthalate induces malformations by decreasing fetal testosterone synthesis during sexual differentiation in the male rat. Toxicol Sci. 2000; 58:339-349. [PubMed: 11099646]

Parmar D, Srivastava SP, Seth PK. Effect of di(2-ethylhexyl) phthalate (DEHP) on spermatogenesis in adult rats. Toxicology. 1986; 42:47-55. [PubMed: 2879365]

Sharpe RM, Skakkebaek NE. Testicular dysgenesis syndrome: mechanistic insights and potential new downstream effects. Fertil Steril. 2008; 89(2 Suppl.):33-38. [PubMed: 17675002]

Silva MJ, Samandar E, Preau JL, Reidy JA, Needham LL, Calafat AM. Quantification of 22 phthalate metabolites in human urine. J Chromatogr B Analyt Technol Biomed Life Sci. 2007; 860:106112.

Skakkebaek NE, Rajpert-De Meyts E, Main KM. Testicular dysgenesis syndrome: an increasingly common developmental disorder with environmental aspects. Hum Reprod. 2001; 16:972-978. [PubMed: 11331648]

Srivastava SP, Srivastava S, Saxena DK, Chandra SV, Seth PK. Testicular effects of di-n-butyl phthalate (DBP): biochemical and histopathological alterations. Arch Toxicol. 1990; 64:148-152. [PubMed: 2350234] 
Swan SH. Environmental phthalate exposure in relation to reproductive outcomes and other health endpoints in humans. Environ Res. 2008; 108:177-184. [PubMed: 18949837]

Swan SH, Elkin EP, Fenster L. Have sperm densities declined? A reanalysis of global trend data. Environ Health Perspect. 1997; 105:1228-1232. [PubMed: 9370524]

Swan SH, Brazil C, Drobnis EZ, Liu F, Kruse RL, Hatch M, Redmon JB, Wang C, Overstreet JW. Geographic differences in semen quality of fertile U.S. males. Environ Health Perspect. 2003; 111:414-420. [PubMed: 12676592]

Swan SH, Main KM, Liu F, Stewart SL, Kruse RL, Calafat AM, et al. Decrease in anogenital distance among male infants with prenatal phthalate exposure. Environ Health Perspect. 2005; 113:10561061. [PubMed: 16079079]

Talsness CE, Andrade AJ, Kuriyama SN, Taylor JA, vom Saal FS. Components of plastic: experimental studies in animals and relevance for human health. Philos Trans R Soc Lond Ser B, Biol Sci. 2009; 364:2079-2096. [PubMed: 19528057]

Teitelbaum SL, Britton JA, Calafat AM, Ye X, Silva MJ, Reidy JA, Galvez MP, Brenner BL, Wolff MS. Temporal variability in urinary concentrations of phthalate metabolites, phytoestrogens and phenols among minority children in the United States. Environ Res. 2008; 106:257-269. [PubMed: 17976571]

Thompson RC, Moore CJ, vom Saal FS, Swan SH. Plastics, the environment and human health: current consensus and future trends. Philos Trans R Soc Lond Ser B, Biol Sci. 2009; 364:21532166. [PubMed: 19528062]

Travison TG, Araujo AB, O'Donnell AB, Kupelian V, McKinlay JB. A population-level decline in serum testosterone levels in American men. J Clin Endocrinol Metab. 2007; 92:196-202. [PubMed: 17062768]

Vermeulen A, Verdonck L, Kaufman JM. A critical evaluation of simple methods for the estimation of free testosterone in serum. J Clin Endocrinol Metab. 1999; 84:3666-3672. [PubMed: 10523012]

Wang C, Christenson P, Swerdloff R. Editorial: clinical relevance of racial and ethnic differences in sex steroids. J Clin Endocrinol Metab. 2007; 92:2433-2435. [PubMed: 17616637]

Wyde ME, Kirwan SE, Zhang F, Laughter A, Hoffman HB, Bartolucci-Page E, Gaido KW, Yan B, You L. Di-n-butyl phthalate activates constitutive androstane receptor and pregnane $\mathrm{X}$ receptor and enhances the expression of steroid-metabolizing enzymes in the liver of rat fetuses. Toxicol Sci. 2005; 86:281-290. [PubMed: 15901914] 


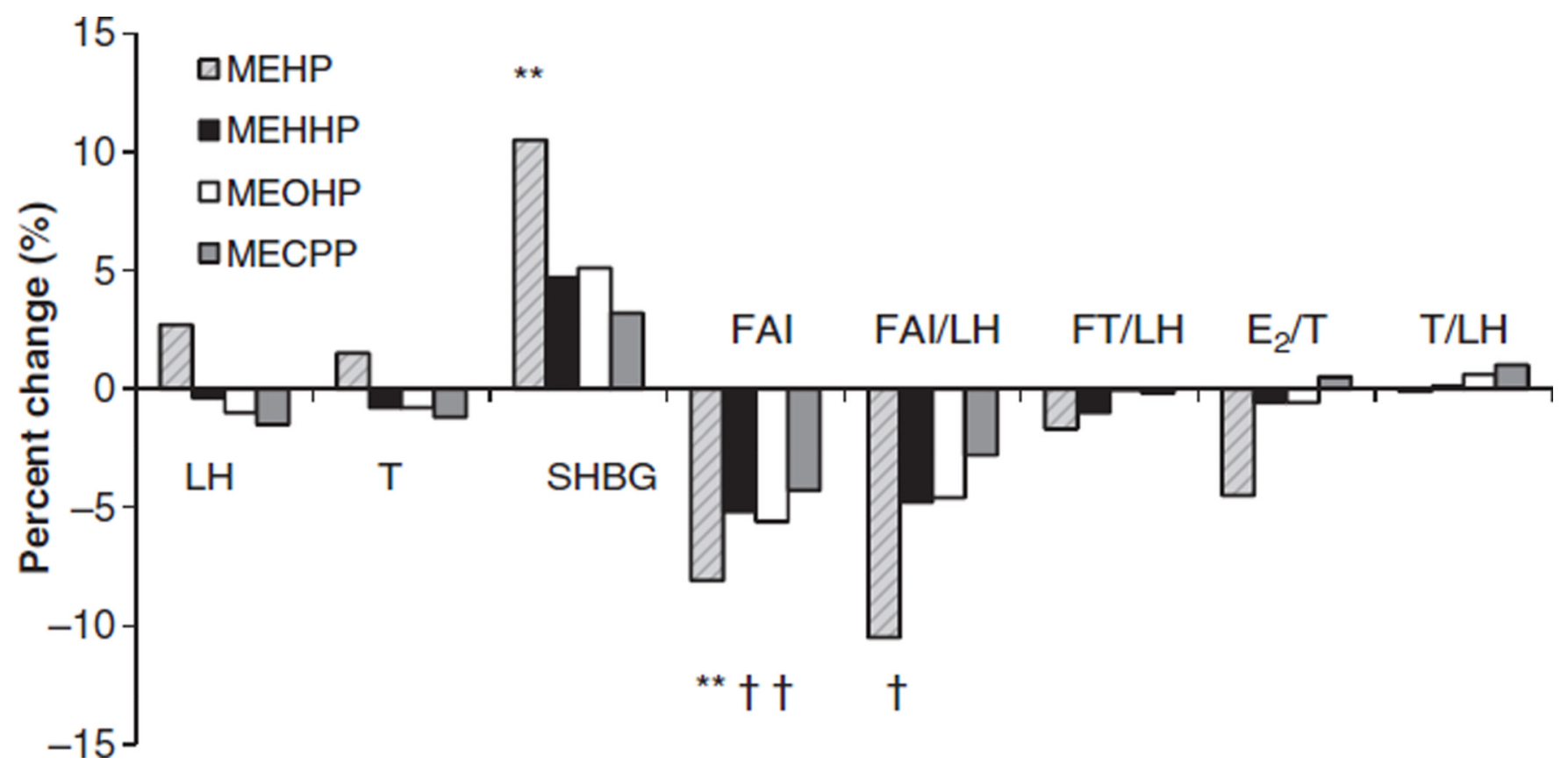

Figure 1.

Percentage change in men's reproductive hormones expected with an interquartile increase in di(2-ethylhexyl) phthalate metabolite concentrations for a standard subject (32-year-old non-smoker with body mass index of $28 \mathrm{~kg} / \mathrm{m}^{2}$ ). Values are statistically significant ${ }^{\dagger} p$ value $\leq 0.05$ and $* * p$-value $\leq 0.01$ ) in the multivariate analysis. 


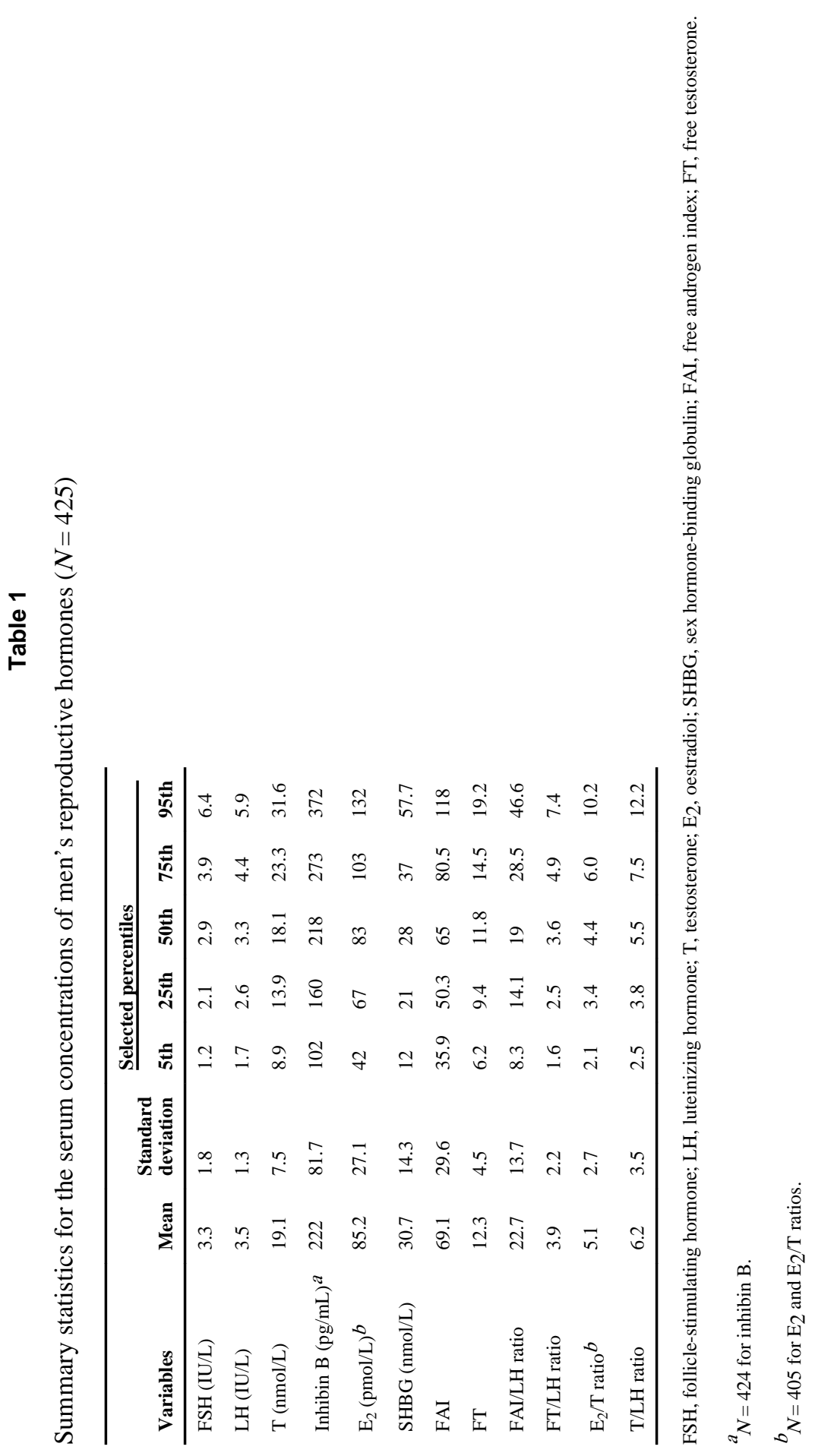




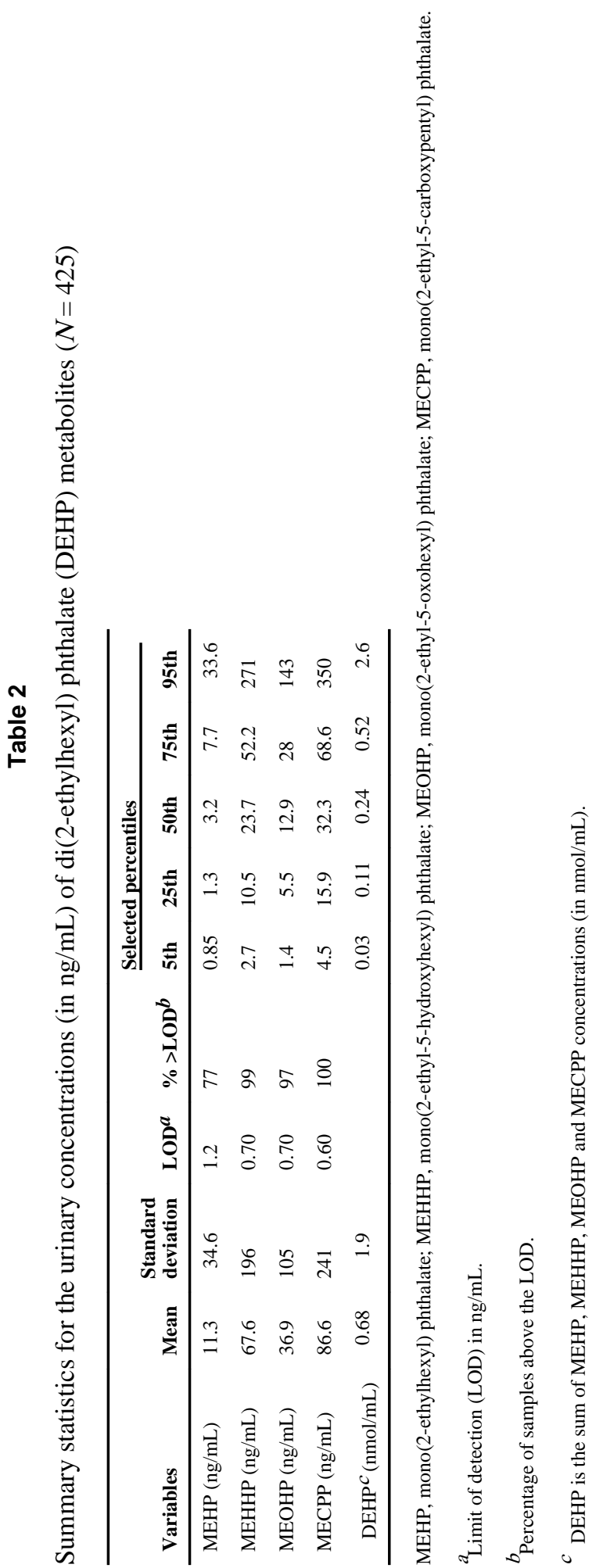

Int J Androl. Author manuscript; available in PMC 2012 December 24. 


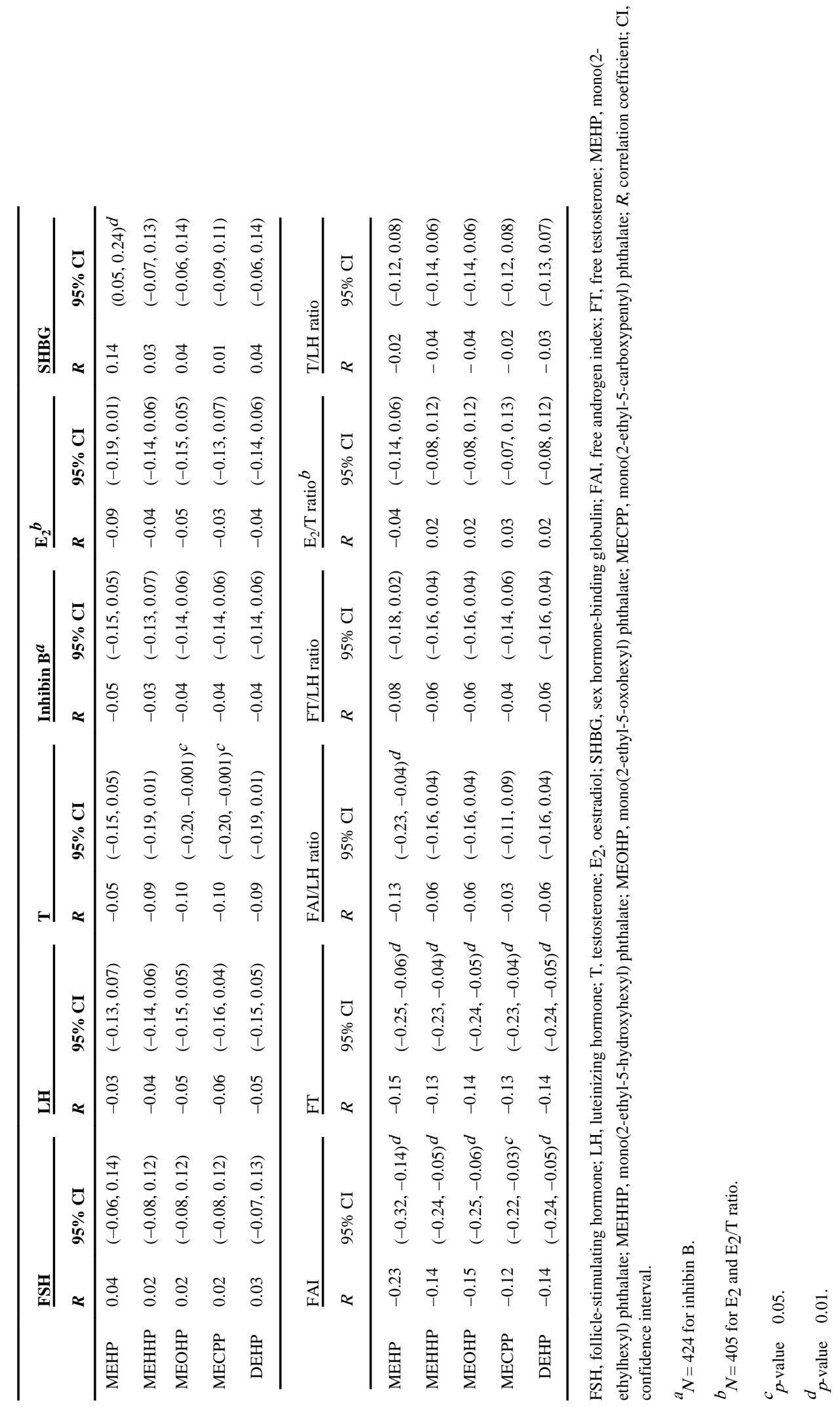




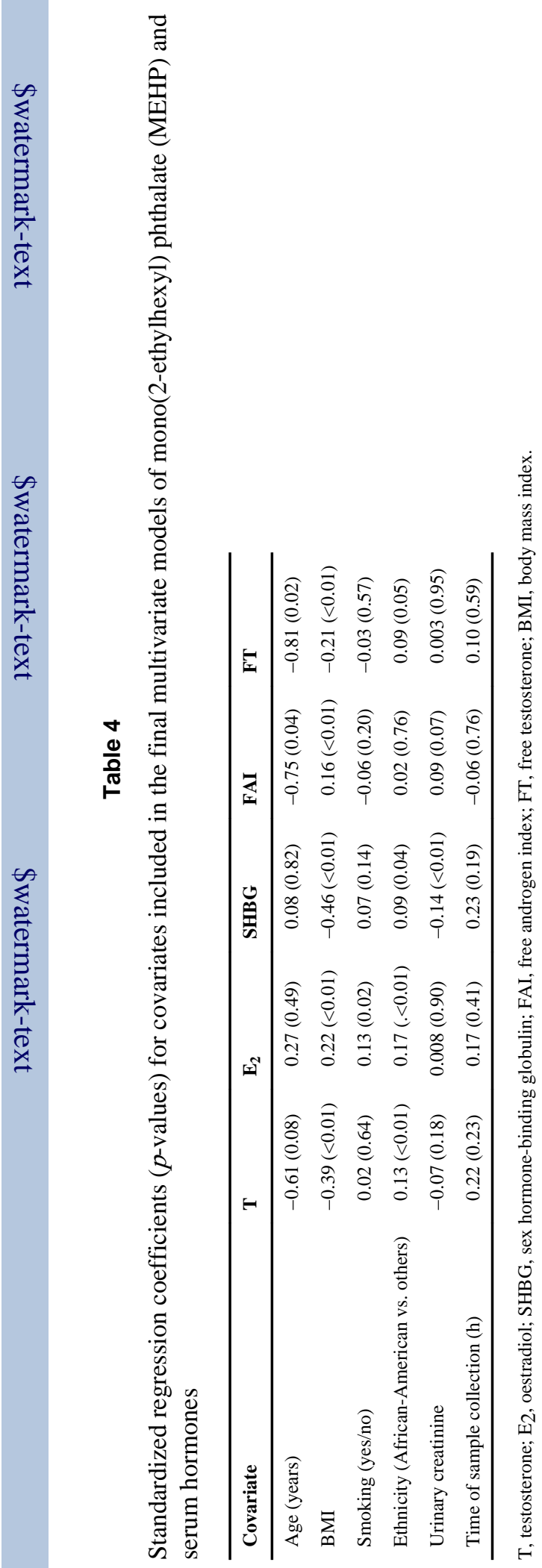




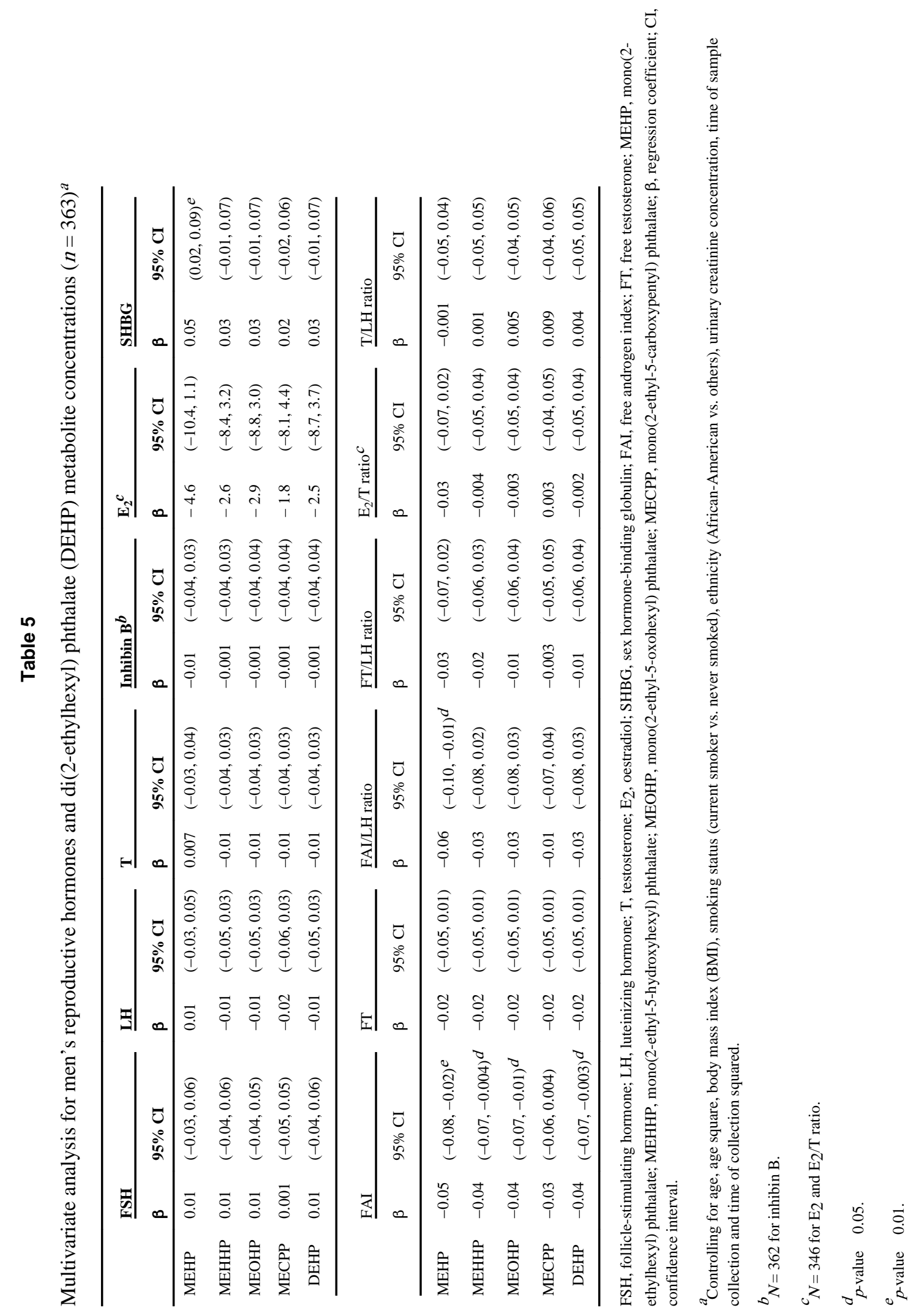

